\title{
A alfabetização científica em atividades didáticas para educação em saúde por meio do uso de textos de divulgação científica: uma pesquisa bibliográfica
}

\section{The scientific literacy in teaching activities for health education through the use of popularization of science texts: a literature review}

\author{
${ }^{1}$ Tatiana de Paiva Zucareli Teles tatizucareli@yahoo.com.br \\ ${ }^{1}$ Jane Raquel Silva de Oliveira
}

\section{RESUMO}

Os textos de divulgação científica (TDC) abordam diversos temas presentes no cotidiano das pessoas, como, por exemplo, aspectos relacionados à saúde. Dessa forma, podem vir a ser adotados no contexto escolar como recurso para educação em saúde. O objetivo deste trabalho foi analisar, em publicações da área de ensino de ciências, a presença da alfabetização científica (AC) em atividades didáticas envolvendo o uso de TDC na abordagem de temas relacionados à saúde no contexto escolar. A busca foi realizada em: revistas da área de Ensino de Ciências; anais do Encontro Nacional de Pesquisa em Educação em Ciências; e anais do Encontro Nacional de Ensino de Biologia. Os dados indicaram que a maior parte das atividades envolvendo o uso de TDC para educação em saúde foi direcionada a promover o entendimento das relações existentes entre ciência, tecnologia e sociedade relativos ao tema saúde, bem como a compreensão básica de termos e conceitos científicos da área. Com menor frequência, encontramos atividades que remetiam à compreensão da natureza da ciência e dos seus aspectos éticos e políticos.

Palavras-chave: Educação em saúde. Texto de divulgação científica. Alfabetização científica. Atividade didática. Pesquisa bibliográfica.

\begin{abstract}
The Popularization of Science Texts (PST) address several important topics in people's daily lives, such as, for example, aspects related to health. Thus, they can be adopted in the school context as a resource to health education. The aim of this research was to analyze, in science education publications, the presence of scientific literacy (SL) in teaching activities involving the use of PST to approach health issues in the school context. To do this, a survey was carried out in these bibliographic fonts: the national scientific journals of the science education area; annals of the National Meeting of Research in Science Education; and annals of the National Meeting of Biology Teaching. The data indicated that most activities involving the use of TDC for health education were aimed at promoting both an understanding of the existing relationships among science, technology and society related, as well as a basic understanding of scientific terms and concepts of health area. Less frequently, we find activities that refer to the understanding of the nature of science and its ethical and political aspects
\end{abstract}

Keywords: Health education. Popularization of science text. Scientific literacy. Teaching activities. Literature review. 


\section{INTRODUÇÃO}

Tanto cientistas quanto educadores defendem que o acesso ao conhecimento científico e tecnológico, bem como o entendimento de suas aplicações na sociedade, é de essencial importância em uma sociedade democrática, de modo que os cidadãos possam se posicionar e tomar decisões com autonomia e consciência (VALÉRIO; BAZZO, 2006). Nessa perspectiva, Sasseron e Carvalho (2011, p.2) colocam a alfabetização científica (AC) como um dos objetivos centrais da educação em ciências. Para as autoras, a AC deve ser um "elemento norteador na elaboração dos currículos para dar conta de promover um ensino capaz de levar os alunos a investigarem temas das Ciências e a discutirem suas inter-relações com a sociedade e o ambiente”.

Cabe destacar que AC não é promovida apenas no contexto formal de ensino. A divulgação científica (DC) e seus diferentes veículos de comunicação também exercem importante papel nesse processo. Dentre os diversos suportes de educação não formal, os textos de divulgação científica (TDC) têm sido um dos veículos mais utilizados no contexto escolar. Esses textos, em geral, não são produzidos especificamente para serem utilizados em sala de aula. Porém, devido à qualidade gráfica, conteúdo atualizado e a linguagem acessível, eles tornam-se materiais que se aproximam do contexto escolar (GIORDAN; CUNHA, 2015).

Para Martins, Nascimento e Abreu (2004), os TDC podem ser utilizados de diversas formas, seja como motivador, como parte de explicações, como provocador de debates ou como fonte de curiosidades, envolvendo temas importantes do cotidiano do aluno, como é o caso da saúde. Nesse sentido, os TDC tornam-se aliados à Educação Saúde (ES) praticada na escola, uma vez que esta, segundo Iervolino e Pelicioni (2005), deve trabalhar no aluno desde os cuidados básicos de higiene pessoal, aquisição de hábitos saudáveis, até estimular a capacidade reflexiva do aluno frente a acontecimentos de saúde/doença.

Considerando que alguns TDC veiculam informações diversas sobre saúde, sendo em alguns casos adotados na educação formal como recurso para abordagem de tais tema, esta pesquisa teve como objetivo investigar, em publicações da área de ensino de ciências, aspectos da AC presentes em atividades didáticas envolvendo o uso de TDC para ES.

\section{REFERENCIAIS TEÓRICOS}

Segundo Fornazari e Obara (2018), as definições acerca da AC, apesar de sua variação semântica na literatura, convergem para a necessidade de promover uma formação crítica, reflexiva e autônoma dos educandos acerca de temas sobre ciência e tecnologia. Nessa perspectiva, apontam que o ensino de ciências, incluindo a ES, têm se alicerçado em alguns fundamentos da AC, reconhecendo que essa formação deve ir além da compreensão científica e tecnológica acerca de temas relacionados à saúde, mas também o entendimento de suas implicações sociais, políticas, ambientais etc.

Compreendendo a AC em uma perspectiva mais ampla, Fourez (2005) listou alguns critérios para que uma pessoa seja alfabetizada cientificamente, dentre os quais se destacam: utilizar critérios científicos e integrar valores e conhecimentos para tomar decisões responsáveis na vida cotidiana; compreender que a sociedade exerce um controle sobre as ciências e as tecnologias, do mesmo modo que as ciências e tecnologias o fazem marcando a sociedade; compreender que a sociedade exerce um controle sobre as ciências e as tecnologias pelos canais das subvenções que ela lhes concede; reconhecer tanto os limites como as utilidades das ciências e das tecnologias para o progresso do bem estar humano; conhecer os principais conceitos, hipóteses e teorias científicas e ser capaz de aplicá-los; apreciar as ciências e as tecnologias pela estimulação intelectual que elas suscitam; compreender que a produção do conhecimento científico depende dos processos de investigação e dos conceitos teóricos; saber reconhecer a diferença entre os resultados científicos e as opiniões pessoais. 
A partir de uma revisão sobre as características e habilidades de AC discutidas por diferentes autores, Sasseron e Carvalho (2011) propõem os Eixos Estruturantes da AC. O primeiro eixo está relacionado à compreensão básica de termos, conhecimentos e conceitos científicos fundamentais e envolve a "possibilidade de trabalhar com os alunos a construção de conhecimentos científicos necessários para que seja possível a eles aplicá-los em situações diversas e de modo apropriado em seu dia-a-dia” (p.75). A compreensão da natureza das ciências e dos fatores éticos e políticos que circulam sua prática descreve o segundo eixo, e está associado "à ideia de ciência como um corpo de conhecimentos em constantes transformações por meio de processo de aquisição e análise de dados, síntese e decodificação de resultados que originam os saberes” (p.75). O terceiro eixo diz respeito ao entendimento das relações entre ciência, tecnologia, sociedade e meio-ambiente, abarcando a "identificação do entrelaçamento entre estas esferas e, portanto, da consideração de que a solução imediata para um problema em uma destas áreas pode representar, mais tarde, o aparecimento de um outro problema associado" (p.76).

Mohr (2009) sustenta a ideia de que a AC seja um potente instrumento conceitual para se alcançar a ES formadora. Nessa perspectiva, a autora destaca as principais características da ES baseada na AC:

autonomia do indivíduo através da competência e reflexão; valorização da escola como núcleo de difusão de conhecimentos; valorização do ensino de ciências e da ciência como instrumento privilegiado de conhecimento e explicação do mundo; significação do conhecimento escolar e utilização dele na vida cotidiana do aluno (MOHR, 2009, p. 122).

Hansen (2016) também concorda que, por meio da AC, a ES poderá romper com a prática baseada na saúde pública, que apenas se importa em prevenir as doenças e transmitir a informação, sem desenvolver no aluno sua reflexão, criticidade e autonomia.

Nesse sentido, é importante ressaltar que apenas a inserção de temas da saúde em sala de aula não garante uma formação pautada nos preceitos de uma AC, pois, conforme Andrade e Abílio (2018), embora a dimensão prática AC esteja relacionada à contribuição do conhecimento científico para resolução de problemas básicos que afetam diretamente a vida do indivíduo, o simples fato de considerar o cotidiano dos alunos nas ações de ensino não garante que esteja sendo trabalhada, de maneira efetiva, a dimensão política da AC.

Fornazari e Obara (2018), ao discutirem as relações entre AC e o ensino de nutrição, reportam que a educação na perspectiva da AC deve favorecer não somente a abordagem de conceitos específicos da área, mas também desenvolver nos estudantes autonomia e consciência em relação a seus hábitos alimentares e de vida, ou ainda estimular uma atuação cidadã voltada à análise e fiscalização de políticas públicas sobre saúde.

\section{METODOLOGIA}

Esta pesquisa é do tipo bibliográfica (FERREIRA, 2002), na qual foram mapeadas e discutidas, sob a perspectiva da AC, produções acadêmicas que reportaram atividades didáticas aplicadas em sala de aula para abordagem de temas relacionados à saúde usando como recurso TDC. O levantamento foi realizado nos anais das doze edições do Encontro Nacional de Pesquisa em Educação em Ciências (ENPEC) e das sete edições do Encontro Nacional de Ensino de Biologia (ENEBio), bem como em 26 revistas científicas nacionais da área de ensino de ciências. Em tais fontes, a busca foi realizada desde a primeira edição do evento ou da revista até a última publicação disponível na internet em outubro de 2020.

Para escolha das revistas, buscamos inicialmente aquelas listadas na Classificação Qualis CAPES atualmente disponível (ano base 2016) para a área de Ensino, com conceito A1, A2 ou B1. Dessa listagem, selecionamos aquelas que tinham como foco e escopo editorial a publicação de trabalhos específicos na área de "ensino de 
ciências" ou "educação em ciências” ou "saúde e educação", sendo elas: Ciência \&Educação; Interface: Comunicação, Saúde e Educação; Acta Scientiae: Revista de Ensino de Ciências e Matemática; Alexandria - Revista de Educação em Ciências e Tecnologia; Areté - Revista Amazônica de Ensino de Ciências; Contexto \& Educação; Ensaio - Pesquisa em Educação em Ciências; Revista Dynamis; Ensino, Saúde e Ambiente; Investigações em Ensino de Ciências; Revista Brasileira de Ensino de Ciência e Tecnologia; Revista Brasileira de Pesquisa em Educação em Ciências; Revista de Educação, Ciências e Matemática; Revista Práxis; Rencima - Revista de Ensino de Ciências e Matemática; Trabalho, Educação e Saúde; Tear - Revista de Educação, Ciência e Tecnologia; Biota Amazônica; Ciência \& Ensino; Ciência em Tela; Ensino de Ciências e Tecnologia em Revista; Experiências em Ensino de Ciências; Revista Ciências \& Ideias; Revista de Educação Popular; Revista Contexto \& Educação; Revista Eletrônica Debates em Educação Científica e Tecnológica.

Para busca dos trabalhos, foi feita a leitura de todos os títulos de todas as edições. Quando encontrado algum título que pudesse estar relacionado ao foco da pesquisa, líamos o resumo e se, ainda gerasse alguma dúvida, realizávamos a leitura na íntegra do trabalho. Para seleção dos trabalhos (corpus da pesquisa), foram adotados os seguintes critérios: ser trabalho completo de evento ou artigo de revista; relatar o uso de TDC em atividade didática aplicada na sala de aula da educação básica (ensino fundamental e ensino médio); e abordagem, nas propostas didáticas, de temas relacionados à saúde.

A análise dos dados foi de natureza qualitativa, adotando-se a metodologia de Análise Textual Discursiva (MORAES, 2003). Nesse processo, lançamos o olhar para unidades de análise extraídas de diferentes partes dos trabalhos: as justificativas que os autores apresentaram para a escolha do TDC; os objetivos didáticos propostos; a descrição dos procedimentos (estratégias) adotados na atividade didática; e a discussão apresentada pelos autores sobre as relações entre o texto escolhido e a atividade desenvolvida. Essas unidades foram agrupadas em três categorias definidas a priori, de acordo com os Eixos Estruturantes da AC (SASSERON; CARVALHO, 2011).

\section{RESULTADOS E DISCUSSÃO}

Foram localizados 15 trabalhos nos quais se reportam atividades didáticas para ES por meio do uso de TDC, sendo sete encontrados nos anais do ENEBio, um no ENPEC e cinco em revistas da área de ensino de ciências (Quadro 1). Considera-se esse número pequeno, tendo em vista que a busca abarcou um considerável número de trabalhos, uma vez que foram investigadas todas as publicações disponíveis até 2020, desde a primeira edição, em 26 revistas e em todos os anais do ENPEC e ENEBio. Esse dado evidencia que as relações entre TDC e ES no contexto escolar ainda são pouco exploradas nos estudos da área.

Na análise desses trabalhos, buscamos identificar que aspectos da AC puderam ser articulados e/ou desenvolvidos pelos estudantes em tais propostas. Observamos inicialmente que nem todos eles contemplavam de forma evidente no texto aspectos da AC. Em alguns trabalhos, embora abordassem o tema saúde em sala de aula e adotassem TDC na proposta didática, o uso desse recurso foi descrito de forma muito superficial, não possibilitando perceber uma relação clara com o desenvolvimento de aspectos da AC. A seguir, apresentamos resultados da análise de acordo com os eixos estruturantes da AC. 
Quadro 1- Trabalhos que reportam atividades didáticas para ES por meio do uso de TDC, publicados nos anais do ENPEC e do ENEBio e em revistas do ensino de ciências.

\begin{tabular}{|c|c|c|c|c|}
\hline $\mathbf{N}^{\mathbf{o}}$ & Ano & Título & Fonte & Autores \\
\hline $\mathrm{T} 1$ & 2004 & $\begin{array}{l}\text { Clonagem na sala de aula: um exemplo do uso } \\
\text { didático de um TDC }\end{array}$ & $\begin{array}{l}\text { Investigações em } \\
\text { ensino de ciências }\end{array}$ & $\begin{array}{l}\text { MARTINS, } \\
\text { NASCIMENTO e ABREU }\end{array}$ \\
\hline $\mathrm{T} 2$ & 2010 & $\begin{array}{l}\text { Leitura de textos de ciências de diferentes gêneros: } \\
\text { um olhar cognitivo-processual. }\end{array}$ & $\begin{array}{l}\text { Investigações em } \\
\text { Ensino de Ciências }\end{array}$ & NIGRO E TRIVELATO \\
\hline T3 & 2010 & $\begin{array}{l}\text { Bronzeamento artificial: uma proposta metodológica } \\
\text { dialogando com a educação, ciência e sociedade. }\end{array}$ & III Enebio & $\begin{array}{l}\text { GOMIDE, LIMA e } \\
\text { TKAHASHI }\end{array}$ \\
\hline $\mathrm{T} 4$ & 2011 & Uso de TDC na educação sexual de adolescentes & VIII Enpec & $\begin{array}{l}\text { CIRNE, TORRES, } \\
\text { COSTA, ALMEIDA e } \\
\text { COSTA }\end{array}$ \\
\hline T5 & 2012 & $\begin{array}{l}\text { Os três momentos pedagógicos na educação de } \\
\text { jovens e adultos da rede municipal de educação de } \\
\text { Goiânia - o conteúdo da dengue: I. Problematização }\end{array}$ & IV ENEBio & $\begin{array}{l}\text { LYRA, OLIVEIRA e } \\
\text { BARRIO }\end{array}$ \\
\hline T6 & 2014 & $\begin{array}{l}\text { Uso de textos de divulgação científica no } \\
\text { desenvolvimento de temas de ES na Educação de } \\
\text { Jovens e adultos (EJA) }\end{array}$ & Revista Práxis & OLIVEIRA e ZANCUL \\
\hline $\mathrm{T} 7$ & 2014 & $\begin{array}{l}\text { Percepções de uma professora sobre a aplicação do } \\
\text { enfoque CTS em aula de genética no ensino médio. }\end{array}$ & V ENEBio & SOUZA e TEIXEIRA \\
\hline T8 & 2014 & ES: do tradicional ao inovador & V ENEBio & $\begin{array}{l}\text { CASTRO, FERREIRA, } \\
\text { DIONOR e MARTINS }\end{array}$ \\
\hline T9 & 2016 & $\begin{array}{l}\text { Propostas de Ensino relacionadas com a promoção } \\
\text { da alimentação saudável na escola. }\end{array}$ & VI ENEBio & LEITE, ZANCUL e MÓI \\
\hline T10 & 2016 & $\begin{array}{l}\text { Aplicação didática de textos da revista Ciência hoje: } \\
\text { revelando o enfoque ciência, tecnologia e sociedade } \\
\text { (CTS). }\end{array}$ & VI ENEBio & GOMES \\
\hline T11 & 2016 & $\begin{array}{l}\text { A abordagem CTS no ensino de ciências: o combate } \\
\text { ao aedes aegypti. }\end{array}$ & VI ENEBio & $\begin{array}{l}\text { MIRANDA, BELÉM, } \\
\text { ANJOS, RODRIGUES e } \\
\text { SANTANA }\end{array}$ \\
\hline T12 & 2018 & $\begin{array}{l}\text { As revistas femininas juvenis no aprendizado do } \\
\text { corpo e da sexualidade: uma contribuição para o } \\
\text { ensino de ciências }\end{array}$ & $\begin{array}{l}\text { Ensino, Saúde e } \\
\text { Ambiente }\end{array}$ & CEZAR e VARGAS \\
\hline $\mathrm{T} 13$ & 2018 & $\begin{array}{l}\text { Alimentação Saudável: contribuições de uma } \\
\text { sequência didática interativa para o ensino de } \\
\text { ciências nos anos iniciais }\end{array}$ & $\begin{array}{l}\text { Contexto \& } \\
\text { Educação }\end{array}$ & $\begin{array}{l}\text { VESTENA, SCREMIN e } \\
\text { BASTOS. }\end{array}$ \\
\hline T14 & 2019 & $\begin{array}{l}\text { A adulteração de alimentos presente em reportagens: } \\
\text { a química, a mídia e a operação carne fraca na sala } \\
\text { de aula }\end{array}$ & $\begin{array}{l}\text { Experiências em } \\
\text { Ensino de Ciências }\end{array}$ & $\begin{array}{l}\text { KADOOCA e SILVEIRA } \\
\text { JÚNIOR }\end{array}$ \\
\hline T15 & 2019 & $\begin{array}{l}\text { O uso didático de texto de Divulgação Científica nas } \\
\text { escolas: discutindo o consumo de antibióticos }\end{array}$ & $\begin{array}{l}\text { Ensino, Saúde e } \\
\text { Ambiente }\end{array}$ & $\begin{array}{l}\text { FONTOURA e } \\
\text { DECCACHE-MAIA }\end{array}$ \\
\hline
\end{tabular}

Fonte: dados da pesquisa 


\section{COMPREENSÃO BÁSICA DE TERMOS, CONHECIMENTOS E CONCEITOS CIENTÍFICOS FUNDAMENTAIS}

Encontramos menções a aspectos relacionados à compreensão básica de termos, conhecimentos e conceitos científicos fundamentais em 60,0\% dos trabalhos, sendo eles: T1, T3, T4, T6, T7, T10, T12, T14 e T15. Em T14, por exemplo, os autores adotaram diversas reportagens publicadas em revistas e jornais para abordagem do tema adulteração de alimentos. Dentre as discussões tecidas por meio desses materiais, os autores mencionam alguns conteúdos conceituais trabalhados na sequência didática, conforme transcrito a seguir:

Mostramos aos estudantes alguns aditivos alimentares mais comumente utilizados. Discutimos que a presença de determinadas funções orgânicas nas estruturas químicas desses aditivos proporciona determinadas propriedades para o composto, relacionando com o modelo de interações intermoleculares. (T14)

Cabe destacar que a apropriação de conceitos por meio do TDC não ocorre necessariamente de forma direta pelos alunos a partir da leitura do material. Cabe ao professor promover o processo de mediação, destacando e discutindo conceitos abordados do TDC que considera importante. Esse aspecto é mencionado em T1 e T15:

A leitura do texto é interrompida sempre que a professora pretende elucidar termos e conceitos. Explicação dos termos neologismo e clonar... (T1, grifo nosso).

Ao longo da leitura, as professoras interrompiam para que os assuntos abordados nele pudessem ser melhor explicados e discutidos.(T15)

Fourez (2005) descreve que uma pessoa como alfabetizada científica e tecnologicamente deve saber utilizar os conceitos científicos e tomar decisões responsáveis no seu dia a dia. Esse tipo de habilidade foi almejada na atividade didática descrita no T3:

Pretendemos assim, levar o aluno a interagir com seu meio, possibilitando discussões e análises sobre os assuntos e privilegiando a sua postura ativa, tornando-o, desse modo, capaz de relacionar objetos e acontecimentos e perceber semelhanças e diferenças. (T3)

Na perspectiva da ES, Mohr (2002) reforça a ideia de que a escola deve conferir ao aluno sabedorias relacionadas à saúde para que ele possa tomar decisões conscientes, ajudando-o a querer, poder e saber escolher comportamentos próprios.

Sasseron e Carvalho (2011), quando fazem menção a esse primeiro eixo estruturante da AC, ressaltam também a importância disso para o aluno compreender acontecimentos no seu cotidiano. Essa perspectiva foi observada em alguns dos trabalhos analisados, os quais ressaltaram o papel dos TDC neste contexto, conforme ilustram os trechos abaixo:

Nossos resultados mostraram que, nesta aula, o TDC funcionou como elemento estruturador [...]. Assim, foi possível estabelecer relações com o cotidiano dos alunos. (T1)

A professora percebe que as estratégias didáticas empregadas proporcionam o estabelecimento de interconexões entre a vida e o conteúdo científico-tecnológico [...] promovendo reflexões e a compreensão crítica sobre a realidade. (T7)

Mello e Guazzelli (2011) afirmaram que o conhecimento técnico e científico sobre saúde é imprescindível para que o aluno tenha melhor qualidade de vida, obtenha maior prevenção de doenças e consiga tomar decisões 
mais conscientes baseadas no seu conhecimento. Nesse sentido, a ES com objetivo apenas de repasse de informação ou de mudanças de comportamento está ultrapassada. Esta deve apresentar-se no ensino formal com o objetivo de desenvolver no aluno o conhecimento, a crítica e a reflexão.

No T6, os autores, ao abordarem a temática alimentação por meio do uso de vários TDC, observaram que a proposta contribuiu para que os alunos conseguissem estabelecer essa relação entre o aprendizado de conceitos e seu cotidiano, conforme destacado a seguir:

Relacionar o texto com as vivências pessoais dos alunos também foi um opção sempre presente nas aulas, como forma de problematizar a realidade vivenciada com o conhecimento científico apresentado nos textos (T6).

Outra habilidade de um sujeito cientificamente alfabetizado, na perspectiva de Fourez (2005), reside na compreensão das aplicações das tecnologias e das decisões implicadas nessas utilizações. Segundo o autor, essa compreensão também abarca a capacidade de compreender um aparelho e saber como utilizá-lo. Dessa forma, observamos no T3 uma menção à necessidade de tal habilidade pelos estudantes:

É preciso que os alunos saibam, por exemplo, como funciona uma câmara de bronzeamento e quais são os princípios e conceitos científicos relacionados ao funcionamento do mesmo... (T3).

Percebe-se, portanto, que o uso de atividades envolvendo TDC para abordagem de temas sobre saúde pode favorecer a $\mathrm{AC}$ dos estudantes no que se refere à apropriação de conceitos que os possibilitem compreender algumas intervenções e práticas da ciência e tecnologia que circundam seu dia a dia. Tais propostas didáticas estão de acordo com um dos objetivos da ES na escola, a qual, conforme Iervolino e Pelicioni (2005), deve contribuir para a apropriação de conhecimentos que antes o aluno não tinha.

\section{COMPREENSÃO DA NATUREZA DAS CIÊNCIAS E DOS FATORES ÉTICOS E POLÍTICOS QUE CIRCUNDAM SUA PRÁTICA}

Este eixo foi identificado em 33,3\% dos trabalhos, sendo eles: T1, T7, T8, T10 e T14. Segundo Ferreira e Queiroz (2012), os TDC têm sido adotados no ensino de ciências no sentido de possibilitar a abordagem de aspectos da natureza da ciência, fazendo com que os alunos tenham contato com o processo de construção da ciência e não apenas considerá-la como pronta e acabada. Nessa perspectiva, no T1, por exemplo, os autores reportam que durante o desenvolvimento das atividades foi possível abordar algumas técnicas usadas nas pesquisas científicas, bem como discutir com os alunos aspectos da natureza da ciência:

Ao término da leitura, a professora faz uma síntese da explicação da técnica empregada na clonagem da ovelha. [...]

Assim, foi possível estabelecer relações com o cotidiano dos alunos, ampliar seu universo discursivo, e ressaltar aspectos da natureza da prática científica. (T1)

Essa discussão presente em T1 remete a algumas habilidades de AC citadas por Fourez (2005), tais como a capacidade de compreender a maneira como as ciências e tecnologias foram produzidas ao longo da história. Essa percepção é importante para a educação em ciências e, também para a ES, porque ela possibilita ao indivíduo ter uma visão mais crítica sobre as informações que chegam até ele nos diversos meios de comunicação. 
No T10, o autor reporta que, durante a atividade, um dos alunos questionou o tempo que se leva para produzir pesquisas desse nível de complexidade e importância social, e a professora explicou o fato do desenvolvimento científico estar atrelado a questões econômicas como o financiamento. Para o autor:

Essa abordagem auxilia a superação de visões neutras, apolíticas e a-históricas da Ciência e da Tecnologia que, despretensiosamente, têm sido muitas vezes ensinadas nas aulas de Ciências deste país”. (T10)

A abordagem de aspectos éticos que circundam a prática da ciência também foi observada no T1, conforme exemplificado no trecho a seguir:

A professora traz para discussão as consequências éticas e morais que a clonagem humana traria para nossa sociedade (T1, grifo nosso)

Em T14, ao abordarem o papel das mídias na veiculação de informações sobre ciência em uma sequência de ensino, os autores observaram que essa discussão também suscitou reflexões sobre a (não) neutralidade da ciência:

Esses trechos evidenciam a consciência dos estudantes sobre as possíveis consequências positivas e negativas que o uso da Ciência pode resultar, já que esta é financiada por grupos de pessoas para atender a seus interesses ou necessidades da época (T14)

Também nesta perspectiva, o T10 faz referência ao aspecto religioso, o que sempre proporciona discussões sobre o processo de produção do conhecimento científico:

Ao abordar os benefícios do desenvolvimento científico em questão, principalmente seus reflexos em relação à saúde, a professora e os alunos discutiram sobre a doação da medula óssea e ressaltaram a influência do aspecto religioso neste processo (T10)

Cabe destacar que a inserção de tais aspectos no contexto escolar favorece o desenvolvimento de habilidades de AC, como a capacidade de fazer a distinção entre resultados científicos e opinião pessoal - as ideias religiosas sobre a clonagem, por exemplo. Além disso, pode favorecer aos alunos uma melhor compreensão sobre o fato de que "é direito da sociedade controlar racionalmente o uso dos conhecimentos científicos e tecnológicos, uma vez que é esta mesma sociedade quem fomenta a atividade dos cientistas” (SASSERON; CARVALHO, 2011, p.68).

\section{ENTENDIMENTO DAS RELAÇÕES EXISTENTES ENTRE CIÊNCIA, TECNOLOGIA, SOCIEDADE E MEIO-AMBIENTE}

Observamos em 60,0 \% dos trabalhos que essa perspectiva da AC foi contemplada, sendo eles: T1, T3, T6, T7, T9, T10, T11, T14 e T15. Muitas dessas propostas estavam pautadas na abordagem Ciência, Tecnologia e Sociedade (CTS), como, por exemplo, na atividade didática reportada no T3, na qual os autores abordaram a questão do bronzeamento artificial, conforme exemplo a seguir:

Optamos por uma abordagem CTS para permitir que os diferentes conteúdos disciplinares possam compor um amplo espaço de debate do tema, abrigando desde a compreensão do processo de interação da radiação solar com a matéria orgânica (pele), o papel da tecnologia com o desenvolvimento de protetores e bronzeadores solares e a percepção e uso de todo esse conhecimento pela comunidade local. (T3)

No trabalho T11 é realizada uma proposta de ensino também pautada na abordagem CTS para trabalhar a ES com os alunos. Ao justificarem essa abordagem, os autores relatam: 
uma proposta de ensino de Ciências pautado na abordagem de ensino CTS deve ter como uma de suas principais finalidades a capacitação dos estudantes para uma tomada de decisão sobre ciência e tecnologia e assuntos que envolvem suas realidade, requisito essencial à formação para cidadania (T11).

Outro aspecto da AC relativo a este terceiro eixo diz respeito à questão das fontes de informação científica e sua importância quando da tomada de decisões (FOUREZ, 2005). Em T6 e T14, os autores trazem para discussão o papel das mídias como fonte de informação e como elas influenciam as decisões dos sujeitos nas situações cotidianas:

\begin{abstract}
Após a leitura fizemos uma reflexão sobre os aspectos abordados no texto e seus hábitos de consumo alimentar, a influência da mídia [...] Em seguida, cada aluno respondeu a uma questão pessoal: qual influência da mídia sobre você? (T6)
\end{abstract}

A proposta de tema 2 permitiu discutir com maior foco a influência que a mídia exerce sobre a população, atendendo aos interesses de grandes grupos que a controlam/manipulam (T14).

A inserção de aspectos relativos a este eixo da AC é coerente com muitas das perspectivas mais atuais sobre ES. Diniz, Oliveira e Schall (2010) trazem a ideia de que a ES é um processo continuado em que os temas mais relevantes da atualidade devem ser incluídos naquele ano no currículo escolar. As questões sobre saúde que estão em debate na sociedade, no local onde vivem, na comunidade que frequentam, devem ser trazidas para a escola, fazendo com que o aprendizado contemple compreensões acerca da sociedade e ambiente.

\title{
8 CONSIDERAÇÕES FINAIS
}

O pequeno número de trabalhos encontrado neste levantamento possivelmente reflete a carência de publicações de estudos abordando a temática ES e suas interfaces com a DC no ensino de ciências, o que evidencia um tema a ser mais explorado na área.

Na análise dessas atividades didáticas quanto à presença de elementos da AC, verificamos que maior parte envolveu o entendimento das relações existentes entre ciência, tecnologia, sociedade e ambiente, pautadas em muitos casos na abordagem CTS. Muitas delas envolveram também a compreensão básica de termos e conceitos científicos básicos. Ou seja, nessas atividades, o TDC parece funcionar como fonte de informação conceitual ou de reflexão acerca das implicações sociais e relações com o cotidiano dentro do tema saúde.

Poucas atividades, no entanto, remetiam à compreensão da natureza da ciência e de seus fatores éticos e políticos. Considera-se, aqui, um aspecto a ser repensado nesse tipo de atividade, uma vez que, para que o indivíduo possa ter uma visão crítica e tomar decisões conscientes sobre saúde, seja ela individual ou coletiva, é necessário que ele compreenda a forma como o conhecimento científico nesse campo é construído, quais os fatores internos e externos que influenciam esse processo, seu contexto histórico e cultural, o papel do cientista, os métodos empregados etc. Esse tipo de compreensão é fundamental para que se possa promover de fato uma AC plena e uma ES mais crítica e reflexiva.

Ademais, concluímos que o uso de TDC para abordagem da ES na educação básica formal representa um caminho para abordagem de alguns conceitos relativos à saúde por meio de uma linguagem mais acessível e atraente. Além disso, favorecem o contato com temas atuais e contextualizados sobre saúde, trazendo novas discussões para alguns tópicos que já fazem parte do cotidiano escolar ou, até mesmo, proporcionando conhecimentos que não fazem parte do currículo formal, mas que são necessários à compreensão de sua realidade e sua capacidade de tomar decisões conscientes sobre sua saúde. 


\section{REFERÊNCIAS BIBLIOGRÁFICAS}

ANDRADE, M. J. D.; ABÍLIO, F. J. P. Alfabetização científica no ensino de biologia: uma leitura fenomenológica de concepções docentes. Revista Brasileira de Pesquisa em Educação em Ciências, v. 18, n. 2, p. 429-453, 2018.

DINIZ, M. C. P; OLIVEIRA, T. C; SCHALL, V. T. Saúde como compreensão de vida: avaliação para inovação na educação em saúde para o ensino fundamental. Revista Ensaio - Pesquisa em Educação em Saúde, v. 12, n. 1, p. 119-144, 2010.

FERREIRA, L. N. A.; QUEIROZ, S. L. Textos de divulgação científica no ensino de ciências: uma revisão. Alexandria - Revista de Educação em Ciência e Tecnologia, v. 5, n. 1, p.3-31, 2012.

FERREIRA, N. S. A. As pesquisas denominadas “estado da arte”. Revista Educação \& Sociedade, ano XXIII, n.79, p.257-272, 2002.

FORNAZARI, V. B. R.; OBARA, A. T. A alfabetização científica em nutrição humana: intersecções e divergências. Amazônia: Revista de Educação em Ciências e Matemáticas, v. 14, n. 30, p. 123-140, 2018.

FOUREZ, G. Alfabetización Científica y Tecnológica: acerca de las finalidades de la enseñanza de las ciencias. Buenos Aires: Colihue, 2005.

GIORDAN, M; CUNHA, M.B. A divulgação científica na sala de aula: implicações de um gênero Divulgação Científica na sala de aula: perspectivas e possibilidades. In: GIRODAN, M; CUNHA, M.B. (orgs) Divulgação Científica na sala de aula. Ed. Unijuí, 2015. p.67-86.

HANSEN, K.S. A formação de professores para o desenvolvimento da Educação em Saúde na escola: investigando o currículo de um curso de pedagogia. 2016. Dissertação (Mestrado em Educação Científica e Tecnológica). Universidade Federal de Santa Catarina, Florianópolis/SC, 2016.

IERVOLINO, S. A.; PELICIONI, M. C. F. Capacitação de professores para a promoção e ES na escola: relato de uma experiência. Revista Brasileira de Crescimento e Desenvolvimento Humano, v. 15, n. 2, p.99-110, 2005.

MARTINS, I; NASCIMENTO, T. G; ABREU, T.B. Clonagem na sala de aula: um exemplo de uso didático de um TDC. Investigação em Ensino de Ciências, v. 9, n. 1, p. 95-111, 2004.

MELLO, L; GUAZZELLI, I. A alfabetização científica e tecnológica e a educação para a saúde em ambiente não escolar. Revista Brasileira de Ensino de Ciência e Tecnologia, v. 4, n. 1, p.22-41, 2011.

MOHR, A. A natureza da Educação em Saúde no ensino fundamental e os professores de ciências. Tese (Doutorado em Educação). Universidade Federal de Santa Catarina, Florianópolis/SC, 2002.

MOHR, A. Educação em Saúde na escola: panorama e questionamentos a partir de depoimentos de professores de ciências de Florianópolis. In: SELLES, S.E.; FERREIRA, M.S.; BARZANO, M.A.L; SILVA, E.P.Q. (org). Ensino de Biologia: histórias, saberes e práticas formativas. Uberlândia: EDUFU, 2009. p.107-129.

MORAES, R. Uma tempestade de luz: a compreensão possibilitada pela análise textual discursiva. Revista Ciência e Educação, v. 9, n. 2, p.192-211, 2003.

SASSERON, L. H; CARVALHO, A. M. P. Alfabetização Científica: uma revisão bibliográfica. Investigações em Ensino de Ciências, v. 16, n. 1, p.59-77, 2011.

VALÉRIO, M. BAZZO, W. A. O papel da divulgação científica em nossa sociedade de risco: em prol de uma ordem de relações entre ciência, tecnologia e sociedade. Revista de Ensino de Engenharia, v. 25, n. 1, p.31-39, 2006.Submetido em: 05-08-2019 